\title{
Adaptive Learning Systems: Beyond Teaching Machines
}

\author{
Nuri Kara \& Nese Sevim \\ Middle East Technical University, Turkey
}

\begin{abstract}
Since 1950s, teaching machines have changed a lot. Today, we have different ideas about how people learn, what instructor should do to help students during their learning process. We have adaptive learning technologies that can create much more student oriented learning environments. The purpose of this article is to present these changes and its effects on learning environment. First, after explaining the concepts of teaching machines and adaptive learning systems including their main features as well as integral components, similarities and differences between these technologies are discussed briefly. Then, following the discussion on weaknesses and strengths of adaptive learning systems, what instructional designers should consider in developing and using them are mentioned.
\end{abstract}

Keywords: Adaptive learning; Adaptive learning systems; Teaching machines; Instructional design; Instructional technology

\section{Introduction}

Adaptive systems have been of great importance in today's world. Besides engineering and technological fields, education area also focuses on these systems in its technology based applications. Compared to teaching machines, are these systems really new form of teaching machines which were developed and used during 1950s? This paper aims to answer this question by comparing two systems in details.

\section{Teaching Machines}

According to Holland (1960), teaching machines were devices providing a finely graded series of problems and giving immediate responses called as rewards or reinforcement for the students' correct answers. Similarly, Casas (2002) stated that "teaching machines were used to control the presentation of frames, keep records of students' answers, and evaluate, score and reinforce correct behavior immediately either by controlling and advancing the next frame or by displaying the correct answer" (p. 14). From these statements, it can be reached that teaching machine was a simple electronic system following a direct path in instruction, aiming at strengthening the desired behaviors of the students.

\section{Pressley's Machine}

Pressley was the first developer of such systems including stimulus materials, response and reinforcement (Stolurow \& Davis, 1965). It was a device that asked a single question to the 
student. If the student knew the answer, he moved to the next question. If not, the question was presented again on the screen until he found the correct answer. This machine allowed students to proceed at their own rate (Skinner, 1958) and recorded their progress (Seattler, 1990). Skinner (1958) opposed Pressley's machine. For him, although this machine was designed for teaching, it was developed against a background of psychological theory (Skinner, 1958). According to Skinner (1958), Pressley understood that students had different pace but he did not do anything to change it. His device was designed to avoid forgetting not for effective teaching. They were kind of testing device so they had to be used after some amount of knowledge gained from somewhere else (Skinner, 1958).

\section{Skinner's Machine}

Skinner who was the later developer of teaching machines mostly emphasized on programs as well as the hardware component to revive the automated instruction (Stolurow \& Davis, 1965). The important difference of Skinner's teaching machines from earlier versions was that students needed to follow a carefully designed sequence of small steps to acquire complex behavior (Skinner, 1958). Acquiring the desired behavior was the ultimate goal of the teaching machines. The principles behind these machines were also provided to understand the structure of it effectively.

Skinner designed the teaching machine based on his programmed instruction method. It was an attempt to obtain behavioral control achieved in the laboratory (Holland, 1960). Based on his experiments conducted in laboratory with animals, Skinner proposed an idea that "by arranging appropriate contingencies of reinforcement, specific forms of behavior can be set up and brought under the control of specific classes of stimuli" (Skinner, 1958, p. 970). However, the reinforcement has to be given immediately after the response of students because the delay between the response and reinforcement of a few second reduce the effectiveness of the reinforcement. In traditional classroom environment, it was difficult for teacher to provide reinforcement just after the correct responses were given; some kind of machines like teaching machines was needed to help the teachers. Skinner describes his teaching machine as a machine that created opportunities to apply principles of learning in terms of practice of the correct responses, immediate feedbacks and reinforcements for the right answer, and small steps with hints (cited in McKeachie, 1974). Using different programs with determined steps in teaching machines made learning environment automatized in reaching several behaviors.

According to Holland (1960), immediate reinforcement, gradual progression from simple to complex, fading, control of the student's observing, discrimination training, and letting student write the program were the emphasized principles behind teaching machines. Immediate reinforcement was the main feature of the teaching machines. In structure of these machines, each correct answer was reinforced to provide learning. Additionally, gradual progression was implemented to reach the complex behavior step by step. For the fading principle, the support of the stimulus was withdrawn gradually (Holland, 1960). Teaching machines controlled attention of the students to concentrate on the program. These machines also strengthened the discrimination which was necessary for learning the desired behavior. For the last principle, teaching-machine materials were revised in accordance with the student's responses (Holland, 1960). 
In light of the views from the literature, the general characteristics of teaching machines can be summarized as; presenting questions or subject matter in small steps to the user in a determined way, giving immediate feedback/reaction regarding the answer of the user, providing reinforcement for the correct answers, and scoring the overall performance of the user.

\section{Advantages of Teaching Machines}

According to its proponents, there are many benefits of teaching machine both for students and teachers. First of all, it provided an opportunity for students to study at their own paces (Skinner, 1958). Using teaching machines, students could take as much as time they need to study the content. In addition, as stated by Skinner (1960), it inspired the students and gave them high degree of competence and confidence. The students were provided buttons in terms of "guessing", "maybe", "sure", so by pressing those buttons after giving the answers, they estimated their level of confidence. By this method, they learned to evaluate their confidence and adopt a useful strategy. Third, unlike the other media such as television and radio, students were active while they were using teaching machine during their learning process (Skinner, 1960). It was a kind of private tutor which alerted students and kept them busy during their learning process (Skinner, 1958). Moreover, with immediate feedback provided by teaching machines, students were able to see how much they knew without waiting for an hour test or final examination.

Teaching machines also provided an alternative medium for teachers for the instructional activities. As Casas (2002) emphasized, presenting information, monitoring students activity, and grading students' work were started to be handled by these machines. Teaching machines were also devices that did not require any other system to carry out the instructional activities. Finally, teaching machines kept the responses of the students and informed the teacher. By this, teachers observed what students understood item by item (Skinner, 1960). Casas (2002) pointed out that teaching machines helped teachers identify the weaknesses of students. Students' responses to specific questions provided by programs in teaching machines were the key items to determine the deficiencies of them.

\section{Disadvantages of Teaching Machines}

Despite the benefits as stated above, some educators and researchers were against the usage of teaching machines. For the opponents, one of the major problems about teaching machines was its one-way characteristic. Teaching machines were poorly designed (McKeachie, 1974). They were not readily portable and required maintenance (Calvin, 1969). It was difficult and time consuming to prepare programs for teaching machines; implying that the teacher must be clear about what he/she wants to teach and should determine the steps of the content at the beginning of the program preparation (Skinner, 1960). Moreover, the content in teaching machines was divided to the frames and all students had to go through frames in linear sequence (Seattler, 1990). The machine forced students to take the steps identified by the instructor in a prescribed order (Skinner, 1958) They did not let the students to see the correct answer until they responded correctly or altered their answer after they saw the correct answer (Calvin, 1969). As Casas (2002) stated, students could not refer to previous questions or answers in flow of the program. 
Another disadvantage was becoming unsocialized because of interacting only with the machine. Casas (2002) also pointed out that affective needs of the students were not taken into consideration. Moreover, the machines did not motivate the students to go on studying because it was assumed that being right is the sufficient reinforcement (Holland, 1960). Thus, boredom was the major complaint of the students in learning from teaching machines and some of them even destructed their machine. Finally, though some students successfully completed the program, they were unable to pass the necessary tests (Seattler, 1990). Due to these problems, by the late 1960 s, the popularity of teaching machines was decreased.

\section{Contributions of Teaching Machines to Learning Environments}

Despite their problems, teaching machines had great contribution in learning environment. As stated by Seattler (1990), they revived the early ideas of individualizing instruction. They fostered the development of technology in instructional programs and influenced number of programs in 1960 s as well as 1970 s. Finally, teaching machines promoted computer assisted instruction and system approach to instruction (Seattler, 1990).

\section{Adaptive Systems}

According to Chieu (2005), "adaptability is the ability of a learning system to provide each learner with appropriate learning conditions to facilitate his or her own process of knowledge construction and transformation" (p. 70). Francois (2011) defines adaptive learning as a usage of technology to help the students in their learning process. It provides content and services to meet the needs of individuals or groups (Martinez, 2003). Similar to these views, Paramythis and Loidl Reisinger (2004) point out that adaptive learning environments include monitoring activities, interpreting these activities based on the domain-specific models, analyzing user preferences out of the interpreted activities, and representing these in associated models to dynamically facilitate the learning process. Based on these statements, facilitation can be considered as a common term. Hence, the description of adaptive learning environments can be summarized as facilitating the learning process of each individual with appropriate learning conditions. As stated by Nguen and Do (2008), learning environment is complex structure that includes many students who has different characteristics. They physically and mentally are different, so do their preferences. Thus, adaptation to these differences in educational environment is necessity (Nguyen \& Do, 2008) and adaptive learning environments provide systems to achieve this.

Categories of adaptive learning suggested by different authors help deeper understanding of this concept. As Paramythis and Loidl Reisinger (2004) stated, there are four major categories necessary for all adaptive learning environments; namely adaptive interaction, adaptive course delivery, content discovery and assembly, and adaptive collaboration support. Paramythis and Loidl Reisinger (2004) define adaptive interaction as providing semantic interactions between the user and the system. They also give importance to the delivery of the course or content in accordance with the characteristics of the learners in adaptive course delivery. For the content discovery and assembly term, they focus on the learning materials or content derived from distributed sources. Authors also believe that adaptive collaboration support involves social interactions between multiple persons in adaptive learning environment. Several researchers have also mentioned about the significance of the adaptive collaboration support. According to Mödritscher, Garcia-Barrios, and Gütl (2004), the main structure of adaptive collaborative e- 
learning is to support group learning and group activities via intelligent coaching. Similarly, the goal of the adaptive collaboration support is to form a group by taking the characteristics of different students into consideration (Brusilovsky, 1999).

Based on the other categorization toward adaptive learning environments in the literature, adaptive presentation of learner contents, adaptive use of pedagogical devices, adaptive communication support, adaptive assessment and adaptive problem-solving support can be implemented by course designer in adaptive learning context (Brusilovsky 1999; Murray 1999; Stoyanov \& Kirschner 2004; as cited in Chieu, 2005). In addition to concepts in the previous categorization, adaptive assessment and adaptive problem-solving support are also among the main concepts of adaptive learning environments. Based on the view of Chieu (2005), adaptive problem-solving support tool in adaptive learning systems can help the learner with hints in the feedback given by using its knowledge-base when the learner decides to take support. For adaptive assessment, adaptive learning systems provide suitable problems to the individual learner, depending on his/her current knowledge (Chieu, 2005).

\section{Advantages of Adaptive Systems}

The proponents of adaptive learning state many benefits of these systems. According to Fischman (2011), with today's advanced technology, the adaptive learning environment has become more efficient and effective. Especially, developments in computer hardware and software allow creating those kinds of adaptive environments. Today, these systems are cheap and they can be used for both online and blended courses. In addition, unlike teaching machine, the order of instruction is defined by students not the instructor or a device. It takes into consideration that everyone has different experience so their knowledge and needs are different. However, traditional classroom environment, especially large classes does not allow instructors to deviate much from the syllabus to meet these needs. As opposed to traditional classroom environment, technology supported adaptive learning helps learners semantically interact with the system.

In adaptive learning systems, the preferences, background characteristics, prior knowledge of each individual can be interpreted by the system efficiently with the help of the technology. The system keeps the student's personal profiles, and based on them, adjust course to the student by providing different levels and presenting each topic, a series of skills and building blocks to master the concepts (Fischman, 2011). Adaptive learning systems can provide adaptive learning materials or adaptive content in accordance with the current situation of each learner from distributed sources in a shortest time. It includes animation, videos, interactive diagrams and other web based features entered when needed by students. Advanced technology enables learners to choose the adaptive content which was not emphasized in ITS.

Adaptive collaboration support which is one of the main categories of adaptive learning environments can be provided with intelligent tutors proposing several learner groups in accordance with the learner's level of knowledge or current cognitive state Adaptive learning systems can monitor each learner's knowledge construction process simultaneously and present scaffoldings and provide immediate feedback in accordance with each learner's expectations. Interactive tutor in the system help students to master of each skill, give short quizzes about the content, keep individual score and offer additional help. Game like environment provided by the system informs students about where they are and what is left 
to do, thus motivate to go on. These systems can be considered as adaptive forms of ITS; hence, they have the capabilities of all ITS as well as adaptive concepts.

Technology supported adaptive learning propose constructed learning context to the user in which he/she can construct own knowledge with several related individual or collaborative pedagogical activities by following the whole progress any time. To summary, in adaptive learning systems, students take the control of their learning process, access to the resources appropriate for their needs and study them at their pace.

The benefits of adaptive learning systems have taken the educators' attention since it offers many capabilities for the instructor. Adaptive learning environment provides opportunities for teacher to apply range of methods. Teacher can either use problem based instruction, case reasoning etc. Moreover, instructors are provided with opportunities to weight the material so that students are directed to high weighted materials to study. In adaptive learning systems, the instructor decides the proficiency level and students do not move forward until they achieve that level. Finally, instructors are informed about the students' process so that they can analyze in which content students face difficulties, by which source they overcome these problems etc.

\section{Disadvantages of Adaptive Systems}

Although the ideas behind the adaptive learning systems are dreams of all educators, the implementation of these ideas is really difficult. While the idea "adaptation based on individual differences" sounds good, it may cause problems if these differences and appropriate methods/materials to pertain these differences are not identified correctly. Nguyen and Do (2008) state that the system must gather information and data about the user and create a user model based on this information. However, which information should be obtained to create successful user model and how should it be obtained? Should system trust the learner to decide the appropriate method for their learning? Adaptive systems designers have to find answers for these questions. Moreover, they have to identify what to adapt. Should the mode of presentations adopt only or the appearance of the system also be adopted?

The system has to identify the differences such as background, prior knowledge about the content, learning style and offers a learning environment to suit these differences. If the systems are not carefully designed, it will not bring advantages only cause problems. The maintenance of adaptive systems is additional weaknesses them. Possible technical or technology related problems can prevent the effectiveness of adaptive learning systems. Since technological knowledge of the teachers may not be adequate to maintain such kind of systems, or students may lack technological knowledge to overcome the problem when they face one.

Finally, there is lack of research about the implementation of this system and lots of questions about them. This is one of the most important weaknesses of these systems. According to Fischman (2011), few studies were conducted to assess the outcomes of these environments. Although some of the studies indicate that students complete the course in shorter time and performed better, effectiveness of these programs are not done in isolation. In other words, researchers examine the effects of multi-featured environment, not isolate one element (Fischman, 2011). Thus, educators may not feel comfortable to implement these technologies into their courses. What it offers and how it accomplishes this should be analyzed and the 
learning results should be investigated deeply. Moreover, it should be investigated what should be adapted, when and how it should be adapted and what should be kept constant in adaptive learning systems. In addition, adaptive learning gets from students either applying pre-test or tracking their progress. It needs to be investigated which method is more effective or whether there should be another method.

\section{Comparison between Teaching Machines and Adaptive Systems: Theoretical Foundations}

The development of adaptive learning systems can be considered as a transformation of teaching machines, thanks to the newly-developed technologies and contemporary learning theories. For instance, with the development of personal computers, the idea of using teaching machines based on programmed instruction was integrated to the advanced computers. In 1990s, computer based instruction was new form of teaching machines, still based on the programmed instruction (Driscoll, 2005). New capabilities of technologies in that time leaded researchers to integrate the idea of programmed instruction to the personal computers. In today's situation, development of new technologies, such as artificial intelligence, and smart systems with the changing paradigm toward learning has created new term called as adaptive learning systems which can also be considered new forms of computer supported systems. Therefore, we can implicitly say that adaptive learning environments are the new forms of teaching machines. In other words, it can be stated that adaptive learning systems have not been emerged instantly; on the contrary, it has been developed parallel with the development of technology and change of the learning conditions from behaviorist to constructivist. It can be considered that teaching machines with the some of the main ideas, such as focusing personalization, monitoring student activity, and giving feedback composed the starting point of the today's adaptive learning systems which also have the similar ideas. That is, it is hard to say that adaptive learning systems are totally different than teaching machines.

The main similarities between teaching machines and adaptive learning systems are their aims. First, both of them aim to help/guide students in their learning process. Furthermore, they acknowledge the fact that each student has a different pace and it was difficult to adapt traditional classroom environment to the pace of all students. Both of them try to create an environment in which students study at their own pace and be active during the learning process. In addition, both of them keep the students' progress and inform the teacher about it. Teacher using one of them can analyze the progress of students and intervene if needed to reach the desired goals.

Although adaptive learning systems cannot totally be differentiated from teaching machines because of their commonalities, the differences between the two systems should also be emphasized to determine the structure of adaptive learning systems. The first difference between teaching machine and adaptive learning is their technologies. Teaching machine was designed in 1920s and spread out in 1950 when technology was not as advanced as it is now. Thus, teaching machines were not portable and it was difficult to modify it for teachers so that teachers had to participate in the design process and decide what he wanted to teach. In contrast, systems in adaptive learning create flexible environment for teachers. They can modify the system based on the needs that may not be predicted at the beginning of the course. The second and the main difference between teaching machine and adaptive learning was the learning theory underlying them. While teaching machines support programmed instruction based on behaviorist principles, today's adaptive learning systems mainly focus on constructivist principles. 
Teaching machines in the education are implementation of behavioral laws using response dependent information to modify or change the behavior (Holland, 1960; Stolurow \& Davis, 1965). Skinner described teaching machines incorporating the principles of learning, namely practice of the correct responses, knowledge of results and reinforcement of the right answer, minimum delay of reinforcement and successive small steps with hints (McKeachie, 1974). These principles focusing on activities only with the behaviors such as practicing, reinforcing, and ordering confirm the idea that these machines are based on behaviorist principles. The basic structure of teaching machines used to aim at giving responses (answers) to stimulus (questions) provided by the machine in sequentially ordered steps, called as programmed instruction by Skinner, by providing immediate feedback as reinforcements. According to Casas (2002), operant conditioning is a process in which behaviors are strengthened or weakened in accordance with the results of the specific behavior. It can be linked from this statement to the structure of the teaching machines requiring immediate strengthening of the correct answers to produce the desired behavior. Content proposed in small steps, sequential procedure, and immediate reinforcement to reach the desired behavior (learning) compose the main elements of the teaching machines. The instructional sequence in the system is so simple that the students hardly make a mistake while using the teaching machines (Saettler, 1990). Students responded to the questions posed by teaching machines and getting reinforcement, they gained the desired behavior such as pronouncing a word or indicating the result of a mathematical equation. There is a logical order in the teaching machine and all of the students have to follow the same path. Although the students are active, the teaching machine decides what question is posed in which order. Since learning is explained as change in the behavior, and learners are integrated to the system in a way of direct instruction, these machines are the application devices of behaviorist principles.

On the other hand, adaptive learning systems mainly emphasize on constructivist paradigm and meet the assumptions of constructivism. According to Ertmer and Newby (1993), the constructivist learning environment emphasizes learner control. In addition, the information is presented in a variety of different ways in terms of its order, modes, perspectives etc. Adaptive learning systems provide opportunities for teachers to apply those assumptions in learning environment. Adaptive learning does not aim to change the behavior of the students by giving reinforcement or force them to follow the start at the same place and follow the same path. Instead, it acknowledges the differences between students and creates learning environments based on these differences. It provides a personalized learning environment for all learners, both by adapting presentation and navigation through the course materials (Retalis \& Papasalouros, 2005). By analyzing learner's profile or learning portfolio, it can dynamically reorganize course resources (Brusilovsky, 2001). It offers opportunity to point and meet the needs of individuals; thus it improves learner's satisfaction with the course and motivates them to complete that course (Dagger, Wade, \& Conlan, 2005). For all these reasons, adaptive learning systems are well beyond teaching machines.

Atif, Benlamri and Berri (2003) state that constructivist model provides following different learning paths to construct individual's own learning in accordance with the characteristics and backgrounds of the individual. Similar to this view, Mödritscher, Garcia-Barrios, and Gütl (2004) reflect that the learner plays an active role in constructing his/her own knowledge through experiences in specific context. Since the aim of the adaptive learning environments is dynamically facilitating the learning of each individual by providing adaptive interactions, adaptive course delivery, content discovery and assembly, and adaptive collaboration support (Paramythis \& Loidl Reisinger, 2004) in accordance with the learning styles, prior knowledge 
and background characteristics, constructivist paradigm is the appropriate approach for these environments. Conditions of learning linked with instructional goals for constructivist philosophy help better understand the major principles. Driscoll (2005) listed these conditions linked with goals as follows:

1. Complex and relevant learning environments - reasoning, critical thinking

2. Social negotiation - retention, understanding and use

3. Multiple perspectives and multiple modes of learning - cognitive flexibility

4. Ownership in learning - self regulation

5. Self awareness of knowledge construction - mindful reflection, flexibility

Adaptive learning systems' ability of producing representative problem situations or content in accordance with the needs of individual learners leads them to critical thinking. Compared to direct instruction, in adaptive learning systems, learners are provided with different learning contexts in which they can carry out the activities to reach their goals. Adaptive collaboration support with intelligent tutoring also creates matching groups or peers in the environment to provide social negotiation. For the purpose of cognitive flexibility, ongoing monitoring and recording of adaptive learning systems guide or advice learners for advance learning and knowledge transfer (Federico, 1999). Adaptive learning systems make learners active by providing dynamic and relevant contexts as well as resources in the environment. These environments allow learners to monitor their own progress in the environment to create self awareness of knowledge construction. Adaptive assessment and adaptive problem solving categories of adaptive learning environments are also consistent with constructivist paradigm. For instance, providing small group works, essays, and projects appropriate to knowledge level of learners in adaptive learning systems helps learners meaningfully learn based on constructivist approach. According to Mödritscher, Garcia-Barrios, and Gütl (2004), dynamic background library of adaptive learning environments supports constructivist learning. Federico (1999) also stated that "an intelligent tutoring system, enabling adaptive instruction in hypermedia environments by employing learners' navigational paths to guide their engagement with the subject matter, can provide the necessary scaffolding that may be sufficient for multiple representations to improve acquisition performance and knowledge transfer" (p. 684).

Another difference between adaptive learning systems and teaching machines was the content they deliver. Teaching machines present the same content for all individuals; on the other hand, adaptive learning systems deal with the learner needs and their characteristics for offering appropriate content or instructional strategies. Lastly, compared to teaching machines which do not include any collaboration among students, adaptive learning systems provide adaptive collaboration support (Brusilovsky, 1999; Mödritscher, Garcia-Barrios \& Gütl, 2004; Paramythis \& Loidl Reisinger, 2004).

Adaptive learning systems can be considered as historically developed systems with with the help of advanced technology and paradigm change toward learning. Teaching machines based on behavioristic paradigm were the starting point of individualized learning. Developing computer technology also integrated programmed instruction into the computers. Intelligent Tutoring Systems (ITS) consistent with "cognitivist view that the instruction should depend on the learner's current cognitive state" (Dalgarno, 2001, p. 185) were also new forms/means of individualized learning. According to Brusilovsky and Nijhawan (2002), ITS present relevant learning material for the individual learner by dynamically selecting from its knowledge base. Compared to teaching machines supporting predetermined steps in learning, ITS changed the 
paradigm to flexible learning. However, most ITS were not based on adaptive choice of content because of general use in schools in which every student learns the same concepts (Melis et al., 2001). In today's situation, adaptive learning systems with the advanced technologies and new paradigm in learning mostly focusing on individual differences and collaboration have created new forms of individualized learning. Since there is a consistent development in terms of individualized learning, it is possible to see the effects of teaching machines and intelligent tutoring systems in adaptive learning systems.

It appears that adaptive learning systems cannot be totally isolated from behaviorist and cognitivist principles. Although the main philosophical background of current adaptive learning systems is constructivism, some concepts of the programmed instruction such as immediate feedback and monitoring student's activity can be integrated as supportive or supplementary tools. Similarly, as Federico (1999) emphasized, cognitive processes should also be integrated in design and development of the adaptive learning systems.

\section{Suggestions to Instructional Designers}

Adaptive learning just includes a system that helps create an effective and efficient learning environment. Thus, without a good design, it will help neither instructors nor students. Since adaptive learning is more suitable to constructivism, instructional designer should apply an appropriate design that meets the basic assumptions of constructivism. First, instructional designer should analyze the content of the course and consider the possible needs of students from different backgrounds, experiences and knowledge levels. To achieve this, he/she should get information about students such as which method or mode of presentation they prefer etc. Based on the relevant information, instructor should prepare content in different modes of presentation and in different level of expertise.

As stated by Stoyanov and Kirschner (2004), the system should be designed in a way that learners should be able to find what they want to learn and how they want to learn it. Learners should be provided feedback to see where they are in the curriculum and what else about the learning task or activity they are going to do next. In addition, learners should be provided opportunities to test the level of their knowledge, their learning styles, and be able to see their learning outcomes. Since adaptive learning systems keep records of student progress, the instructor should monitor each student's progress and see where they are, what problems they face etc. If there is a problem, they should intervene appropriately.

Students should also be provided with opportunities to socialize and reflect what they have learned. They should discuss with their peers and instructors. Besides, instructor should help students collaborate with their peers. He/she should use different modes of group discussion and collaboration with learners (Stoyanov \& Kirschner 2004). If adaptive learning is used by different instructors, instructional designer should inform the teacher about the benefits and weaknesses of the system as well as how they can modify the system if there is a problem. Moreover, he/she should provide guidance and help when needed and support the adaptation process of instructors to use adaptive learning.

Instructional designers need to be involved in the development of adaptive learning systems with system developers. It is important to note that adaptive learning environments should not be developed for a specific domain or subject matter. On the contrary, adaptive learning systems should enable teachers or instructors to integrate a variety of pedagogical devices, 
learning contents and collaboration strategies into the system to improve their uses in education. Consistent with this view, Chieu (2005) points out that adaptive learning systems should be domain independent.

In addition, instructional designers should carefully analyze learner activities to design an adaptive learning environment. As Federico (1999) emphasizes, recognized student activities such as navigational preferences and search options should be taken into consideration in the design of the adaptive interfaces.

Another suggestion toward adaptive learning systems is related to developing these systems based on cognitive flexibility. That is, multiple perspectives in accordance with the knowledge level and the current cognitive state of learners should be provided in the adaptive context. However, adaptive content delivery or presentation strategies in these systems should not increase cognitive load of the learner. The cognitive load principles, such as avoiding split attention and decreasing redundancy proposed by Clark, Nguyen and Sweller (2006), should be implemented during the development of adaptive learning systems.

As the final suggestion, instructional designers should mainly follow constructivist principles in designing adaptive learning systems and integrate compatible components of behaviorist principles (i.e. immediate feedback when learner needs help for a specific problem in the context) along with cognitivist principles (i.e. providing instructional strategies regarding the cognitive state of the learner) as supportive tools.

\section{References}

Atif, Y., Benlamri, R., \& Berri, J. (2003). Learning objects based framework for self-adaptive learning. Education and Information Technologies, 8(4), 345-368.

Brusilovsky, P. (1999). Adaptive and intelligent technologies for web-based education. In C. Rollinger \& C. Peylo (Eds.), Special issue on intelligent systems and teleteaching (Vol. 4, pp. 19-25), Künstliche Intelligenz.

Brusilovsky, P. (2001). Adaptive hypermedia. User Modeling and User Adapted Interaction, 11(1-2), 87-110.

Brusilovsky, P. \& Nijhawan, H. (2002). A framework for adaptive e-learning based on distributed re-usable learning activities. Proceedings of the World Conference on $E$ Learning, E-Learn 2002, Montreal, Canada.

Calvin, A. D. (1969). Programmed instruction. Bold New Venture: Indiana University Press.

Casas, M. (2002). The use of Skinnerian teaching machines and programmed instruction in the United States 1960-1970 (Unpublished doctoral dissertation). Harvard University, 1997. (ERIC Document Reproduction Service No. ED 469942).

Chieu, V. M. (2005). Constructivist learning: An operational approach for designing adaptive learning environments supporting cognitive flexibility (Unpublished doctoral dissertation). Louvain-la-Neuve, BE: Université catholique de Louvain. 
Clark, R. C., Nguyen, F., \& Sweller, J. (2006). Efficiency in learning: Evidence-based guidelines to manage cognitive load. San Francisco, CA: Pfeiffer.

Dagger, D., Wade, V., \& Conlan, O. (2005). Personalisation for all: Making adaptive course composition easy. Educational Technology \& Society, 8(3), 9-25.

Dalgarno, B. (2001). Interpretations of constructivism and consequences for Computer Assisted Learning. British Journal of Educational Technology, 32(2), 183-194.

Driscoll, M. P. (2005). Psychology of learning for instruction (3nd ed). Boston, MA: Allyn \& Bacon.

Ertmer, P. A. \& Newby, T. J. (1993). Behaviorism, cognitivism, constructivism: Comparing critical features from an instructional design perspective. Performance Improvement Quarterly, 6(4), 50-72.

Federico, P. A. (1999). Hypermedia environments and adaptive instruction. Computers in Human Behavior, 15, 653-692.

Fischman, J. (2011). The rise of teaching machines, Retrieved on May 23, 2011 from http://chronicle.com/article/The-Rise-of-Teaching-Machines/127389/

Francois, C. (2011). What is adaptive learning? Retrieved on 24 May 2011 from http://www. wisegeek.com/what-is-adaptive-learning.htm

Holland, J. G. (1960). Teaching machines: An application of principles from the laboratory. Journal of the Experimental Analysis of Behavior, 3, 275-287.

Martinez, M. (2003). Adaptive learning. Retrieved on May 24, 2011 from http://www. trainingplace.com/source/research/adaptivelearning.htm

McKeachie, W. J. (1974). The decline and fall of the laws of learning. Educational Researcher, 128(3), 7-11.

Melis, E., Andrès, E., Büdenbender, J., Frischauf, A., Goguadze, G., Libbrecht, P., Pollet, M., \& Ullrich, C., (2001). ActiveMath: A generic and adaptive web-based learning environment. International Journal of Artificial Intelligence in Education, 12, 385-407.

Mödritscher, F., Garcia-Barrios, V. M., \& Gütl, C. (2004). The past, the present and the future of adaptive e-learning. An approach within the scope of the research project AdeLE. In M. Auer \& U. Auer (Eds.), Proceedings of the International Conference on Interactive Computer Aided Learning (ICL 2004). Villach, Austria: Carinthia Tech Institute.

Nguyen, L. \& Do, P. (2008) Learner model in adaptive learning. Proceedings of World Academy of Science, Engineering and Technology, 35, 396-401.

Paramythis, A.\& Loidl-Reisinger, S. (2004). Adaptive learning environments and elearning standards. Electronic Journal on e-Learning, 2(1), 181-194. 
Retalis, R. \& Papasalouros, A. (2005). Designing and generating educational adaptive hypermedia applications. Educational Technology \& Society, 8(3), 26-35.

Saettler, P. (1990). The evolution of American educational technology. Englewood, CO: Libraries Unlimited.

Skinner, B. F. (1958). Teaching machines. Science, 128, 969-977.

Skinner B. F. (1960). Teaching machines. The Review of Economics and Statistics, 42, 189- 191.

Stolurow, L. M. \& Davis, D. (1965). Teaching machines and computer-based systems. In R. Glaser (Ed.), Teaching machines and programmed learning II: Data and directions (pp. 162-212). Washington, D.C.: National Education Association of the United States.

Stoyanov, S. \& Kirschner, P. (2004) Expert concept mapping method for defining the characteristics of adaptive e-learning: ALFANET project case. Educational Technology Research and Development, 52(2), 41-56.

Correspondence: Nuri Kara, Research Assistant, Department of Computer Education and Instructional Technologies, Faculty of Education, Middle East technical University, Ankara, Turkey 